\title{
Coloquio Internacional de Hermenéutica Analógica
}

\author{
International Colloquium \\ of Analog Hermeneutics
}

\author{
Alaide Lucero Rodríguez \\ Jesús Navarrete Rubio \\ corrosivo_galo@hotamil.com \\ chuchocc7@gmail.com
}

Este año el Coloquio Internacional de Hermenéutica Analógica cumplió 15 años. La decimoquinta edición se celebró los días 24, 25 y 26 de septiembre en el Aula Magna del Instituto de Investigaciones Filológicas. Participaron tanto estudiantes como profesores de distintas universidades nacionales e internacionales, destacando el número de colegas colombianos que asistieron a presentar y discutir sus investigaciones.

El invitado especial del coloquio fue el doctor Jacinto Choza, catedrático de la Universidad de Sevilla y especialista en antropología filosófica, quien inauguró el ciclo de ponencias con una conferencia magistral titulada "Formas de comunicación humana y sobrehumana”, que fue comentada por el doctor Mauricio Beuchot. En ella presentó una serie de notas que surgieron a partir de su investigación sobre filosofía de la religión, en las que se pregunta por la génesis del lenguaje. Parte Choza de un enfoque fenomenológico y, así, considera la comunicación como inherente a la condición de los seres vivientes. En su análisis de las religiones primitivas ha encontrado que las primeras formas de comunicación son los fluidos corporales, como la sangre y el semen, modos simbólicos de autoposesión corporal y temporal. El lenguaje surge como un elemento análogo a ellos, pero la autoposesión es en él espiritual y, por tanto, un desarrollo abstracto y artificial. Hacia el final de su conferencia sugirió una continuidad entre esta realidad artificial, potenciada por la realidad virtual de la lengua escrita, y la interfaz cibernética en la que nos desenvolvemos actualmente. 
En las mesas posteriores se trataron muchas temáticas diversas, relacionadas con la hermenéutica analógica (en adelante, HA) desde su aplicación en otras disciplinas hasta autores, aparentemente lejanos, con los que puede encontrar un diálogo fructífero.

Se presentaron trabajos de hermeneutica utens, o hermenéutica aplicada, que abordaron, por ejemplo, estudios de caso sobre la multiculturalidad en la ciudad de Bogotá y sobre la diversidad religiosa en las islas del Caribe colombiano. Hubo, además, ponencias en torno a las relaciones entre la comunicación y la hermenéutica, proponiendo a esta última como una herramienta complementaría al análisis del discurso y, también, como auxiliar teórico para la ampliación del enfoque de la disciplina. Dos participaciones más versaron sobre la aplicabilidad de la HA a ramas tan distantes entre sí como la hermenéutica jurídica y la enseñanza y el aprendizaje de las lenguas clásicas. Finalmente, se presentó un ejercicio de análisis hermenéutico analógico del documental The Rabbit Hunt (2017).

Las reflexiones estéticas abarcaron a esta disciplina, concebida desde la HA, así como los problemas de la traducción poética y los entrecruces de la analogía, la metáfora y la sinécdoque en el literato jalisciense Arturo Rivas Sáinz. En tónica semejante se trató a autores como Paul Ricoeur, en una divagación en torno a la vida y la ética; y Gilbert Durand, en una introducción a su pensamiento sobre la imaginación simbólica como una resistencia a los embates del neopositivismo. Estos dos autores, salvo algunas especificidades, se ubican dentro del denominado "giro hermenéutico", al que también pertenece la HA. Otra aproximación impensada hasta ahora fue la del existencialismo de Miguel de Unamuno con el pensador ruso Mijaíl Bajtín.

Se destacaron las participaciones que recuperaron los vínculos entre la HA y el llamado nuevo realismo, del que se puede considerar precursora. Algunos propusieron incluso la recuperación de la metafísica y el replanteamiento de la pregunta heideggeriana por el Ser. Esto engarza con la propuesta de una antropología filosófica que tenga como base los presupuestos filosóficos de la HA, para elaborar una ontología de la dignidad del hombre y de los derechos humanos. Todo esto se enmarca en el diálogo constante que la HA mantiene con el pensamiento de la posmodernidad de la que es contemporánea.

Un último sendero reflexivo abordó la necesidad de una ética analógica que pueda dar cuenta de nuestras relaciones con la naturaleza, esto a la vista de la actual catástrofe ambiental y las dinámicas económicas de explotación de lo viviente. 
Por último, dentro del marco del coloquio se tuvo la oportunidad de asistir a la presentación del primer número del volumen 4 de Interpretatio, revista del Seminario de Hermenéutica. En ella participaron la doctora Camila Joselevich y dos de sus colaboradores en el dossier sobre teología política que ella editó para este número. Se destacó el carácter interdisciplinario, colaborativo -artículos escritos a varias manos-, y horizontal que buscó plasmarse en el dossier, y que coincide con el esfuerzo editorial de la revista en general.

Después de los primeros 15 años de este Coloquio Internacional de Hermenéutica Analógica, llama la atención la diversidad de campos de aplicación y desarrollo que esta ha ido encontrando, así como la variedad de interlocutores con los que sigue dialogando. Esperamos se cumplan muchos más.

\section{Alaide Lucero Rodríguez}

Licenciada en Filosofía por la Universidad Nacional Autónoma de México.

\section{Jesús Navarrete Rubio}

Egresado de Filosofía de la Facultad de Filosofía y Letras de la Universidad Nacional Autónoma de México. 